\title{
MMA e a conquista do gosto: disputas e seduções midiáticas
}

\author{
MMA and the conquest of taste: media disputes and seductions \\ MMA y la conquista del gusto: disputas y seducciones mediáticas
}

Recebido: 17/10/2021 | Revisado: 24/10/2021 | Aceito: 24/10/2021 | Publicado: 27/10/2021

\author{
Anna Cristina Brisola \\ ORCID: https://orcid.org/0000-0002-4349-128X \\ Centro Universitário Augusto Motta, Brasil \\ Universidade Federal do Rio de Janeiro, Brasil \\ E-mail: anna.brisola@gmail.com \\ Vinícius Caruzo Monteiro Laino \\ ORCID: https://orcid.org/0000-0002-7182-5603 \\ Universidade Estácio de Sá, Brasil \\ Centro Universitário Augusto Motta, Brasil \\ E-mail: vinicius.caruzo2@gmail.com \\ Rafael Carvalho da Silva Mocarzel \\ ORCID: https://orcid.org/0000-0001-9480-826X \\ Universidade Federal do Rio de Janeiro, Brasil \\ Universidade de Vassouras, Brasil \\ E-mail: professormocarzel@gmail.com
}

\begin{abstract}
Resumo
Ao analisar a história da sociedade humana, as práticas desportivas sempre estiveram presentes, confundindo-se e se misturando com as culturas e sociedades ao redor do mundo. Dentre tais práticas, as lutas sempre ganharam grande destaque, tendo sido utilizadas não apenas para autodefesa ou promoção da saúde, mas também como ferramenta política para o entretenimento da população, integrando fortemente a chamada "política da cultura do pão e circo". Já em tempos contemporâneos, o MMA (Mix Martial Arts) ganhou grande atenção da mídia nos últimos anos, tendo se tornado uma ferramenta midiática de espetacularização, entretenimento e ainda alienação popular. Assim, as mídias televisivas, digitais e impressas têm feito uso do MMA como uma forma de desconstrução e reconstrução do gosto popular. Nessa perspectiva, este estudo aqui apresentado em formato de ensaio acadêmico objetivou se debruçar e refletir criticamente sobre o MMA e a conquista do gosto através de manipulações midiáticas sendo alicerçadas pelos pensamentos de Guy Debord.
\end{abstract}

Palavras-chave: Mídia; MMA; Sociologia esportiva; Sociedade do espetáculo; Gosto.

\begin{abstract}
When analyzing the history of human society, sports practices have always been present, mixing and mixing with cultures and societies around the world. Among such practices, fights have always gained great prominence, having been used not only for self-defense or health promotion, but also as a political tool for the entertainment of the population, strongly integrating the so-called "politics of the culture of bread and circus". Already in contemporary times, MMA (Mix Martial Arts) has gained great media attention in recent years, having become a media tool for spectacularization, entertainment and even popular alienation. Thus, television, digital and printed media have made use of MMA as a form of deconstruction and reconstruction of popular taste. From this perspective, this study presented here in the form of an academic essay aimed to focus and critically reflect on MMA and the conquest of taste through media manipulations, supported by the thoughts of Guy Debord.
\end{abstract}

Keywords: Media; MMA; Sports sociology; Society of the spectacle; Taste.

\section{Resumen}

$\mathrm{Al}$ analizar la historia de la sociedad humana, las prácticas deportivas siempre han estado presentes, mezclándose y mezclándose con culturas y sociedades de todo el mundo. Entre tales prácticas, las peleas siempre han ganado un gran protagonismo, habiendo sido utilizadas no solo para la autodefensa o promoción de la salud, sino también como herramienta política para el entretenimiento de la población, integrando fuertemente la llamada "política de la cultura del pan y circo". Ya en la época contemporánea, MMA (Mix Martial Arts) ha ganado una gran atención mediática en los últimos años, habiéndose convertido en una herramienta mediática de espectacularización, entretenimiento e incluso alienación popular. Así, la televisión, los medios digitales e impresos han hecho uso del MMA como una forma de deconstrucción y reconstrucción del gusto popular. Desde esta perspectiva, este estudio que aquí se presenta en forma de ensayo académico tuvo como objetivo enfocar y reflexionar críticamente sobre el MMA y la conquista del gusto a través de manipulaciones mediáticas, apoyado en el pensamiento de Guy Debord.

Palabras clave: Medios; MMA; Sociología del deporte; Sociedad del espectáculo; Gusto. 


\section{Introdução}

No final da última década do século XX, o $\mathrm{MMA}^{1}$ (Mixed Martial Arts) despontou no espaço midiático esportivo como um fenômeno exaltado e de audiência mundial. Nos primeiros anos do século XXI, o MMA se estabeleceu como um dos maiores espetáculos esportivos da atualidade, envolvendo multidões de expectadores, fãs dedicados, atletas midiatizados e negócios bilionários.

Por muito tempo o esporte sofreu críticas severas, sendo rotulado como um palco para a violência e exaltação da barbárie humana, sofrendo, inclusive, comparações diretas entre os lutadores atuais e o cage (jaula onde ocorrem as lutas) com os gladiadores e o Coliseu, como atualização do circo romano. Mesmo depois de diversas reformulações e normatizações da prática esportiva (nas competições e fora delas), o gosto pelo apelo combativo e feroz do esporte ainda permaneceu causando turbulências (ainda que amenizadas ao longo do tempo). As críticas à prática apontavam os conflitos morais, éticos e estéticos causados pela violência no cage, ainda mais se comparado ao universo esportivo clássico.

Os eventos caracterizados pelos gritos da torcida, duelos muitas vezes ensanguentados, desafios e grosserias entre os rivais nas coletivas de imprensa, extrapolam em muito estas características quando comparados a esportes como o boxe, já tido como violento. Esta face agressiva e sanguinolenta apresenta o MMA como um grande ator mundial daquilo que Debord (2003) chama de Cultura do Espetáculo.

Nessa perspectiva, este estudo aqui apresentado em formato de ensaio acadêmico objetivou se debruçar e refletir criticamente sobre o MMA e a conquista do gosto através de manipulações midiáticas sendo alicerçadas pelos pensamentos de Guy Debord. Sob esta guisa que este estudo explora reflexões, interpretações e mesmo reinterpretações das relações midiáticas do esporte MMA, com mais foco na perspectiva brasileira. Para isto, realizamos uma breve revisão histórica sobre a prática no Brasil e no mundo em seu período germinal no século XX e posteriormente exploramos as relações filosófico sociais do gosto e do espetáculo que constituíram a trajetória do MMA e colaboraram estrategicamente com seu sucesso a despeito das críticas. Como este texto se constituiu no formato de ensaio tendo feito uso de uma revisão narrativa de literatura, a estruturação de uma metodologia científica mais complexificada não se fez necessária. Desta forma, o texto abaixo se apresenta sob um viés crítico-reflexivo, recaindo diretamente sobre diversas esferas socioculturais que perpassam a temática em questão.

\section{A TV, o Vale-Tudo e o MMA: uma história midiática}

Nas primeiras décadas do século XX, a família Gracie ${ }^{2}$ idealizou e promoveu (através de Carlos e Hélio Gracie) o "Desafio Gracie", uma espécie de disputa entre praticantes de Jiu-Jitsu³ da família Gracie contra praticantes de outras modalidades de combate país afora. Era o embrião do UFC ${ }^{4}$.

O Ultimate Ultimate Fighting Championship, evento de MMA mais prestigiado do mundo, surgiu de uma iniciativa de dois empresários e praticantes de Jiu-Jitsu, o norte-americano Art Daves e seu mestre, o brasileiro Rorion Gracie. Desde o início seus idealizadores já pensaram na Televisão como o melhor meio de propagar a ideia do esporte, por isso, seu

\footnotetext{
${ }^{1}$ As Artes Marciais Mistas, mais conhecidas pela sigla MMA são artes marciais que incluem tanto golpes de combate em pé quanto técnicas de luta no chão.

${ }^{2}$ A família Gracie foi a precursora e mais conhecida difusora do Jiu-Jitsu no Brasil, criando adaptações significativamente extensivas, mudando inclusive a terminologia da prática para Jiu-Jitsu Brasileiro ou JJB com o objetivo de diferenciar as técnicas tradicionais oriundas do Japão das desenvolvidas por eles no Brasil (Mocarzel, 2011).

3 Jiu-jítsu é uma arte marcial japonesa que utiliza tanto técnicas de golpes de alavancas, torções e pressões para derrubar e dominar um oponente (Mocarzel \& Columá, 2020).

${ }^{4}$ O Ultimate Fighting Championship é uma organização de MMA que produz eventos ao redor de todo o mundo. Tem sua base atualmente nos Estados Unidos. O primeiro evento promovido pelo UFC ocorreu em Denver, Colorado.
} 
planejamento como evento foi alicerçado em um tripé de criadores: publicitários, empresários e cineastas de Hollywood. A nomenclatura MMA (Mixed Martial Arts) aparece mais tarde, cunhada por Jeff Blatnick, comentarista da TV americana, ao fazer uma explicação do esporte. No Brasil, com a crescente procura e difusão das lutas e artes marciais, o desafio ganhou fama e popularidade, angariando esportistas e fãs, ainda que alguns destes eventos, promovidos como evento esportivo e com público pagante, tenham acontecido modestamente e regionalmente.

No início da televisão brasileira em meados do século $\mathrm{XX}$, algumas formas populares de entretenimento foram selecionadas para complementar a grade de horários das emissoras. É a oportunidade para o nascimento da modalidade "ValeTudo"5 que viria a se popularizar.

(...) Foi no Rio de Janeiro, em 20 de Janeiro de 1951, que o Vale Tudo teve sua primeira transmissão no Brasil. Na inauguração da TV Tupi Rio de Janeiro, foi exibido um programa onde Carlos e Hélio (Gracie) convidaram cinco estivadores, alguns com mais de 100kg, para enfrentarem cinco alunos da Academia Gracie. O público assistiu atônito os franzinos alunos de Jiu Jitsu derrotarem os adversários num show de técnica. (Takao, 2012).

A primeira apresentação do Vale-Tudo, não tinha pretensões de continuidade, era para ser um evento, em transmissão televisiva pontual, uma aposta única da "TV Tupi" já misturando espetáculo com o mundo esportivo. As lutas causaram reações diversificadas no público, revelando, desde então, a dicotomia causada por esta prática esportiva nos expectadores: admiração e repúdio. As mesmas características que escandalizavam (e ainda afrontam) parte das pessoas, encantava (e ainda fascina) outras - as demonstrações violentas de combate, com apelo de veracidade, comprovada pelos ferimentos nos lutadores, que apresentam lesões e cortes notórios.

(...) $\mathrm{O}$ fato era que algumas lutas terminavam de forma violenta e por vezes com atletas ensanguentados e foi justamente por isso que a audiência mostraria um paradoxo que se repetiria com frequência mais tarde. Mesmo repudiando a suposta violência, os críticos não se limitavam a usar a liberdade de escolha trocando o canal, e encontraram na proibição a forma de acabar com o incômodo. (Takao, 2012).

Somente em 1959, o esporte voltou a ser transmitido na televisão. Desta vez, a "TV Continental" criou o programa "Esta noite de vitória", que exibia confrontos das mais variadas lutas e artes marciais, direto do ginásio Gilberto Cardoso (Maracanãzinho), na cidade do Rio de Janeiro. Foi a segunda emissora televisiva brasileira a apostar neste esporte, ainda em seu início. A atração foi transmitida na primeira semana de funcionamento do antigo canal 9. Depois desse primeiro programa, a "TV Continental" passou a contar com o programa semanal "Heróis do ringue" em sua grade fixa. Idealizado por Carlos Gracie, a atração mostrava alguns combates de Vale-Tudo toda segunda-feira. As exibições aconteciam no horário nobre das 20:30, e apresentava seis lutas entre praticantes das mais variadas modalidades e de Jiu-Jitsu.

Segundo o Mestre Reyson Gracie, que atuava como técnico de vários lutadores, a TV Continental lançou o Heróis do Ringue para concorrer com o programa Noite de Gala da Tupi, que passou para o segundo lugar de audiência, criando enorme reação na emissora concorrente. A partir de então, a Tupi passou a criticar o programa acusando-o de "introduzir a violência e a selvageria nos lares". (Takao, 2012).

\footnotetext{
${ }^{5} \mathrm{O}$ Vale-Tudo é uma modalidade de luta com contato pleno em que os adversários nem sempre precisam seguir um único estilo de arte marcial. Por exemplo, um lutador de Jiu-Jitsu pode lutar contra um lutador de Muay Thai.
} 
Como aponta Takao (2012), o sucesso do Vale-Tudo propagado pelo programa "Heróis do ringue", que chegou a ser líder de audiência, gerou ataques e críticas dos concorrentes. A mesma "TV Tupi", consolidada como a maior emissora no Rio de Janeiro, que alguns anos antes havia transmitido um desafio de Vale-Tudo entre estivadores e lutadores de Jiu-Jitsu, tornouse a maior crítica do esporte. Com seus interesses comerciais ameaçados pelo sucesso do Vale Tudo na concorrente, a emissora, a pressão da TV Tupi foi intensa. Usando a alegação de excesso de violência no programa, conseguiu o fim das transmissões de Vale-Tudo na concorrente e ainda fomentou a proibição de seu televisionamento no país em 1961. O argumento foi fortalecido por uma luta transmitida ao vivo em que João Alberto Barreto aplicou uma chave "Kimura" quebrando o braço de José Geraldo, que se recusou a desistir. Depois de dois anos de muita polêmica e sucesso, estava dado o último golpe que selou o fim do programa.

Apesar da polêmica que acontecia entre as emissoras de TV, no início dos anos 60 o esporte ganhou espaço em Pernambuco. Como publicidade para uma fábrica de beneficiamento de algodão, foi criado o programa "Tv Ringue Torre", transmitido semanalmente na "TV Comércio". Por seis anos, a atração se consagrou como o primeiro evento de Vale-Tudo de sucesso longe da capital federal, onde os irmãos Gracie dominavam o esporte. Com o fim do TV Ringue Torre, a modalidade ficou totalmente fora da televisão brasileira até meados da década de 1980 caindo no ostracismo.

Em 30 de abril de 1984, como evento isolado, ocorre no ginásio do "Maracanãzinho" no Rio de Janeiro um desafio entre praticantes do Jiu-Jitsu e do Muay Thai tendo como evento principal o desafio entre Marcelo Behring (Jiu-Jitsu) e Flávio Molina (Muay Thai) seguindo as regras do Vale-Tudo (AWI, 2013). Em 1991 o Vale-Tudo ressurge, quando a Rede Globo de Televisão, maior emissora de TV aberta do Brasil e uma das maiores do mundo, transmite um desafio. A luta principal era entre Eugênio Tadeu, praticante de Luta-Livre, e Wallid Ismail, lutador de Jiu-Jitsu. A reação do público não ajudou a imagem do esporte. O que os responsáveis do evento declararam expõe o problema: "logo no primeiro episódio o telespectador ficou com a impressão de que a TV Globo havia posto no ar, em plena noite de sábado, um festival de pancadaria. Uma luta sem regras, regada a sangue" (transcrição de parte da transmissão do evento - AWI, 2012).

Fora do Brasil, em 12 de novembro de 1993, no McNichols Sports Arena em Denver, Colorado, EUA, Rorion Gracie e Arthur Davie organizam a primeira edição do UFC (Ultimate Fighting Championship), que acaba se tornando o evento mais importante do mundo na modalidade e um dos eventos esportivos com maior repercussão midiática em âmbito mundial. O público inicial era composto por homens agressivos e "brigões".

Vendido como um espetáculo sangrento, uma batalha real onde valia quase tudo, a competição trazia oito lutadores que se digladiavam dois a dois no octogono, aquele que ganhasse três lutas seguidas era proclamado campeão. A ideia do octógono surge com a finalidade de proteger lutadores e público, mas por seu apelo espetacular acompanha o esporte desde então. As regras eram mínimas, proibindo apenas mordidas e perfuração dos olhos, e não existia nenhuma divisão dos lutadores por categorias de peso (Vasques, 2013).

Apenas em 1996 o esporte começou a ser transmitido na TV fechada brasileira em canais fechados e pagos (Pay-perview), particularmente o evento UFC, no canal por assinatura SporTV. Os eventos eram gravados e apresentados em compactos direcionados para o público interessado.

Em 1997, dois eventos marcam o UFC. Angariando notoriedade, público e fãs, Vitor Belfort, com apenas 19 anos, se torna o primeiro ídolo nacional no MMA e o mais jovem campeão do UFC. Por outro lado, como reportado na Revista "Isto é", o esporte voltou a ser visto como algo extremamente violento. Agravando a situação, durante um evento no Rio de Janeiro (não televisionado), um tumulto no público culminou em uma confusão generalizada. O problema vai parar na Assembleia Legislativa do Estado do Rio de Janeiro (ALERJ) através do PROJETO DE LEI No 1727/97, que tem como justificativa 
A proliferação junto à juventude da competição denominada "vale-tudo" vem causando um considerável aumento da violência. Recentemente, em São Paulo, no Maksud Plaza Hotel, durante a realização desse tipo de competição a violência foi tão assustadora que o combate foi encerrado por um Médico devido ao estado físico dos contendores. $\mathrm{O}$ árbitro recebeu recomendações do Médico para que terminasse o combate pois os disputantes estavam banhados em sangue.

Agora verifica-se na sede do Tijuca Tênis Clube, uma verdadeira batalha campal, onde, não apenas os contendores, mas a própria plateia, viu-se envolvida em cenas de brutalidade que estarão cada vez mais se proliferando. (Brasil, 1997).

Em decorrência foi instaurado um decreto de lei proibindo a prática de Vale-Tudo no estado (Brasil, 1997).

Nos Estados Unidos, em 2001, os irmãos Lorenzo e Frank Fertita compram a franquia UFC. Para que o MMA fosse aceito pelas comissões atléticas e voltasse a ganhar espaço, o empresário Dana White começou um movimento de implantação de regras para o exercício do esporte. No Brasil, afastado novamente da mídia, o esporte voltou a entrar em evidência em 2002 com novo nome: MMA - sigla em inglês de Mixed Martial Arts. O Sistema Brasileiro de Televisão (SBT) transmitiu ao vivo o evento "UFC 37.5 - Victor Belfort vs Chuck Liddel”. Mesmo rendendo uma forte audiência, o MMA, novamente, teve uma única transmissão em TV aberta. Entre 2002 e 2009 o segmento foi transmitido exclusivamente no circuito de televisão por assinatura, pelo canal "Premiere Combate" (atualmente "Combate") especializado em lutas, aumentando a popularidade e o público.

O interesse do público é um termômetro de quanto essa modalidade é capaz de mobilizar multidões. Desde 2002, o MMA é o único esporte, além do futebol, a ter um canal exclusivo do segmento no país, que hoje tem 75 mil telespectadores e registrou um crescimento de quase 50\% no primeiro trimestre de 2010 (Gomes, 2016).

Durante este período houve crescimento pequeno e gradual. Os assinantes buscavam principalmente combates envolvendo brasileiros que já tinham destaque ou que lutavam por algum título (cinturão). Destacaram-se neste período os eventos do UFC (estadunidense) e do "Pride Championship" (japonês) que contavam com os principais nomes do MMA mundial. Eventos como os Grand Prix do Pride, em 2003 e 2005 que tiveram campeões brasileiros (Wanderley Silva e Maurício Shogun) e eventos que envolveram brasileiros disputando cinturões no UFC, como Anderson Silva, Vitor Belfort e Rodrigo Minotauro, atraíam o interesse do público para o canal.

Em 2007 a franquia americana comprou o Pride japonês e assim voltou a ser a principal organização de MMA no mundo. No Brasil, o emergente canal Premiere Combate agora contava, essencialmente, com as transmissões do UFC, que já tinha em seu card, elenco de lutadores contratados, atletas mais conceituados. Os campeões do Ultimate Fighting passaram a serem considerados campeões mundiais em seus pesos.

Em 2009 a "RedeTV!" compra os direitos de transmissão do UFC, já a maior organização de MMA do mundo, e passa a transmitir em TV aberta um programa semanal chamado: “UFC sem limites”. A atração exibia lutas passadas e foi exibida até o ano de 2011, quando o esporte ganhava maior atenção da mídia televisiva, digital e impressa.

Quando o UFC voltou ao Rio de Janeiro foi transmitido pela RedeTV! alcançando a maior audiência de sua história. A luta principal, entre o brasileiro Anderson Silva e o japonês Yushin Okami, foi o primeiro evento da organização estadunidense no Rio de Janeiro e a segunda no Brasil. Porém, diferente do que aconteceu em 1997 em São Paulo, desta vez a franquia contou com grande participação das mídias de massa, como TV aberta e fechada, nacional e estrangeira, tendo ainda transmissão em tempo real pela internet. O público também havia mudado, não sendo apenas constituído de praticantes de artes marciais, mas também de fãs que queriam assistir seus ídolos e ícones. 
No momento em que Anderson Silva começou a lutar, a RedeTv!, que transmitia as lutas do card principal, ou seja, as lutas mais importantes, liderou a audiência na TV aberta pela primeira vez na história, com pico de 13 pontos, ou 754 mil televisores só na grande São Paulo, segundo o Ibope (Awi, 2012,p.32).

Em 2012 o reallity show "The Ultimater Fighter" pela primeira vez foi produzido e realizado fora dos Estados Unidos da América (EUA). Esta edição do programa foi considerada pelo presidente da marca como o ápice do esporte no Brasil. O maior evento de MMA do mundo passou não só a ser exibido no país, mas também a ser produzido no Brasil. Depois de centenas de lutas dentro das regras do UFC e da redução dos competidores para 32 candidatos, os combates começam a ser televisionados. Na fase final 16 lutadores são divididos em dois times que se enfrentam. Na primeira das sete edições previstas por contrato entre o UFC e a Rede Globo de Televisão, os treinadores foram Wanderley Silva e Victor Belfort. O formato previa uma luta entre eles ao fim do programa que seria o evento principal.

A intenção deste reallity show é mostrar ao grande público como se dá a preparação dos atletas da modalidade. Como qualquer outro programa de televisão que expõe o dia a dia dos participantes, a intenção é a humanização do lutador. Para servir de ampliador de mercado deste esporte, o programa vende ao público a imagem dos atletas como indivíduos, desmistificando o estereótipo violento, mostrando o atleta e seu esforço (ou não) para chegar ao objetivo final. As imagens cotidianas que antecedem as lutas constroem um espetáculo humanizante e empático que transforma lutadores em atletas com suas limitações, superações e emoções. O gladiador sanguinolento se torna o atleta esforçado e merecedor da vitória.

\section{Esporte, Sociedade e Violência}

Há uma relação íntima e histórica entre esportes e sociedade, como destaca Manoel Tubino (1993, p.12). "A história do desporto é íntima da cultura humana, pois por meio dela se compreendem épocas e povos, já que certo período histórico tem o seu esporte e a essência de cada povo nele se reflete". A influência é mútua, sociedade e esporte se modificam cultural e historicamente.

O sociólogo esportivo Mauricio Murad (2007) descreve a violência como assunto presente em diversas sociedades através de épocas distintas, independentemente da sua escala dentro das sociedades, tanto arcaicas quanto contemporâneas. Maria Cecília Minayo e Edinilsa Souza (1998) apontam a violência como um conceito polissêmico e controverso, ponderando que suas especificidades necessitam de esclarecimento para haver alguma discussão. Concordando com tal pensamento, os professores Rafael Botelho e José Maurício Capinussú de Souza (2007, p.59) alegam que "a violência pode ser caracterizada como problema crônico e recorrente". Por fim, de forma bem mais ampla, Cynara Hayeck (2009) é direta e afirma que a violência pode abranger pensamentos e reflexões políticas, teológicas, econômicas, culturais, educacionais, psicológicas, dentre outras.

Donald Calhoun (1987) explora quatro interpretações de como a violência se insere no meio esportivo. Na primeira opção o autor cita o desporto contribuindo para a diminuição da violência. Neste caso, serviria como uma fuga da tensão e estresse do dia a dia. Fundamentalmente age como mecanismo que controla a violência e agressividade no indivíduo, proporcionando a este um meio de "catarse", oferecendo um contraponto ou prazer a quem pratica o esporte. Outra forma abordada é no sentido contrário, ou seja, o esporte servindo para o aumento da violência. De acordo com este raciocínio, salienta-se que o meio esportivo é um estimulante ao ego para os vitoriosos e uma frustração e decepção para os derrotados. Estes sentimentos conflitantes seriam suficientes para estimular e fomentar manifestações reativas, conduzindo assim ao estímulo da violência.

Na terceira opção analisando a vida em comunidade sob um prisma sociológico, Calhoun (1987) destaca a correlação entre a sociedade e o esporte na existência da violência. Justificando esse pensamento, ele faz alusão às similaridades entre a guerra e o esporte. $\mathrm{O}$ autor traça um paralelo entre os dois e posteriormente tece uma convergência de estimulação mútua, que 
pode, inclusive, auxiliar nos treinamentos. No quarto ponto levantado por Calhoun (1987), é considerado o simbolismo como evidência da violência manifestada no meio esportivo. A violência deveria ser expressa abertamente, no entanto é reprimida. $\mathrm{O}$ autor afirma que no caso da ausência de agressividade no desporto, representada pelas lutas e artes marciais, seriam fomentadas práticas como, por exemplo, as brigas de galo. Elas representariam um "combate simbólico" dos próprios indivíduos espectadores.

Levando em conta os pensamentos abordados, o esporte realmente pode contribuir na diminuição da violência, uma vez que a prática de esportes conta com atividades físicas e cognitivas. Na prática, os desportos têm como características de seus praticantes uma postura disciplinar regrada e colabora com a liberação da agressividade e do estresse acumulado através da atividade física. No cenário das lutas e artes marciais o atleta passa por variadas formas de treinamento e competições que podem contribuir para que não haja acúmulo de sentimentos violentos, liberando esses possíveis sentimentos de maneira adequada e saudável.

Outro ponto que respalda as colocações de Calhoun (1987) são as filosofias ligadas às modalidades. Nelas os mestres não exercem apenas a função de professor da atividade física em si, também são responsáveis por passar ensinamentos que transcendem os limites dos tatames, ringues e/ou octógonos. Eles levam aos seus discípulos ensinamentos acerca da cultura ligada aquela modalidade específica. A luta por seu caráter defensivo e ofensivo, possui um trabalho agregado dos treinadores conscientizando os alunos sobre a necessidade da disciplina e autocontrole, punindo-os em caso de problemas disciplinares e até os proibindo-os de praticar o esporte. Ainda assim, se existe a perspectiva do esporte com o agente auxiliador no combate a violência, é preciso admitir que existem também evidências de que ele também pode, de fato, agir estimulando a violência como já colocado por Calhoun (1987).

O que se vê na sociedade brasileira é que de fato há indivíduos tomando para si os gostos e desgostos dos desportos, evidenciados nos duelos de torcidas organizadas, com violência gratuita e descabida. O que deve ser observado é que a violência entre as torcidas frequentemente independem da vitória ou derrota de seus times. Cabe então um questionamento sobre a origem, de fato, da violência e sua relação com o esporte ou extravasamento através da prática esportiva ou de seus fãs. Para isso sugerimos uma pesquisa mais aprofundada nesse sentido, podendo peregrinar da filosofia para a sociologia, psicologia, antropologia, educação, história, dentre outras grandes áreas de pesquisa.

Uma pista pode estar na terceira opção de Calhoun (1987), quando coletiviza a violência e correlaciona a sociedade e esporte. De fato, não há dúvidas de que as pessoas são influenciadas pelo meio onde vivem, por suas relações sociais, religião, cultura, enfim, o seu habitus ${ }^{6}$, que por sua vez pode influenciar e incitar certas reações ou atitudes.

Calhoun (1987) explicitou na quarta parte o simbolismo como evidência e argumenta que a agressividade deve sim ser exposta à sociedade, como um esporte. Isso pode ser uma relação catártica para essa sociedade ou simplesmente expor seu lado agressivo. De maneira curiosa, a pesquisa doutoral de Gonçalo do Carmo (2016) cita que na perspectiva dos lutadores e espectadores (obviamente simpatizantes), o MMA não seria um esporte violento, embora a literatura e as entrevistas realizadas para pesquisa apontem, sim, uma presença da violência simbólica dentro do universo da prática, para além das competições, envolvendo inclusive o treinamento cotidiano dos praticantes.

$\mathrm{Na}$ televisão, caso deste artigo, a violência é implícita e explícita em vários formatos, desde os desenhos animados feitos para crianças até os filmes de ação, suspense, terror, dentre outros, nos quais é inclusive, desejável. Assim é estranho que a violência no MMA tenha sido o grande entrave para a sua aceitação, mesmo que tenha sofrido diversas transformações de regras e normativas para sua esportivização e progressiva diminuição das manifestações de violência em comparação a seu início (Vasques, 2013).

\footnotetext{
${ }^{6}$ Segundo Bourdieu, “(...) é uma matriz cultural que predispõe o indivíduo a fazer suas escolhas” (Murad, 2009, p.123).
} 
Quando humaniza seus lutadores, cria o circo espetacular, agrega entusiastas, o MMA, associado intimamente ao show midiático, naturaliza sua violência através da admiração pelo esporte em si e pelo espetáculo e assim desperta o gosto pelo esporte. Observa-se que o MMA passa a ter então uma identidade de admiração e repulsa social, de ferramenta econômica empresarial e de mídia interativa que flutua entre a aprovação e reprovação, sendo tudo isso uma materialização, ou mesmo metáfora, da multifacetária opinião e visão da sociedade.

Após uma pesquisa etnográfica, Camilo e Spink (2018) afirmam que hoje o MMA é uma prática esportiva que está imersa no espetáculo e na lógica econômica, tendo uma larga e múltipla atuação no cenário midiático e social brasileiro o que nos remete à Gui Debord (2003), que discutimos mais adiante.

\section{Construção Midiática do Gosto e o MMA}

A sociedade atual possui uma relação íntima com as mídias, com a informação e com a comunicação. Não é a toa que constantemente é denominada de "sociedade da informação". Castells (2003) considera que a informação está atrelada culturalmente à influência das mídias na sociedade. Em uma relação retroalimentada sociedade e mídia se influenciam mutuamente, porém é importante refletir sobre como as agendas da mídia influenciam o gosto dos indivíduos e seus pensamentos a respeito de um determinado assunto ou atividade. Já é de amplo conhecimento que a mídia influencia na sociedade, na cultura e, portanto, no indivíduo.

Capurro e Hjorland (2007) aponta a informação não é idêntica para emissor e receptor e que, no processo de comunicação, é um evento que produz conexão entre as diferenças. Assim, controvérsias sobre um esporte podem ser fomentadas e resolvidas de acordo como as escolhas, comportamento e influência da mídia e de um determinado veículo, como por exemplo, a televisão, que teve e ainda tem um poder comunicacional considerável.

as tecnologias, em especial as tecnologias de comunicação, tem contribuído decisivamente, em especial no último século, para reconfigurar a face das sociedades (...). É necessário, contudo, pensá-la em articulação com a dinâmica social mais ampla, profunda e densa que lhe deu origem, que a atravessa, que a determina de múltiplas formas, mas que é, ao mesmo tempo, em um grau considerável, por ela determinada. (Schneider, 2012, p. 286-287) ${ }^{7}$

Evidentemente, com o MMA não seria diferente, como já exposto no levantamento histórico feito anteriormente, a TV teve participação efetiva e histórica na popularização da modalidade. Da mesma maneira que a visibilidade do esporte foi conferida também pela televisão, essa mesma exposição ao longo dos anos gerou desagrados nos espectadores e na sociedade. Após idas e vindas do MMA na TV, este finalmente se consolidou como programa esportivo e entretenimento de maneira internacional. No Brasil se consagrou com o UFC gravado no país, garantindo visibilidade e espaço ao esporte, inclusive em outras mídias além da TV, ainda que não massivamente.

Obviamente essa relação entre esporte e mídia é pautada de acordo com interesses hegemônicos e financeiros. Os interesses comerciais, na maioria das vezes, determinam ou afetam o que será transmitido. A maneira que a mídia tratou o MMA e que o esporte se desenvolveu a partir da relação com a mídia é uma evidência dessa determinação e influência.

A TV Continental alcançou a liderança nos índices de audiência durante as segundas-feiras quando trazia ao ar programação de Vale-Tudo, incomodando a líder de audiência TV Tupi, no início da década de 1960. A emissora de TV, que

\footnotetext{
${ }^{7}$ Apesar da diferença do texto impresso, a correção foi feita pelo próprio autor do texto, um dos autores deste capítulo, que identificou um pequeno erro na versão publicada do artigo.
} 
então era a detentora do maior público, mais poderosa e prestigiada, lançou mão de articulação política, impulsionando uma campanha para a proibição da veiculação do esporte na TV brasileira. O resultado exitoso da empreitada jog ou a culpa no esporte tachado de violento. Meio século depois, os direitos de transmissão dos eventos de MMA mais assistidos do mundo estão sob a guarda do grupo de televisão com mais influência da TV brasileira, em tendências e formatos. A Rede Globo de Televisão controla o esporte em canais abertos e fechados.

Essa relação de poder, guiada pelo lucro é hoje potencializada pela mídia e por suas ramificações digitais. Apesar das resistências ao MMA decorrentes da violência envolvida no esporte, as artimanhas midiáticas para amenizar essa impressão e humanizar o esporte foram eficazes para a conquista de espaço e de público, inclusive tornando o MMA e seus lutadores brasileiros assunto, até mesmo para quem não acompanha o esporte.

A comunicação jamais esteve tão fortemente entranhada na batalha das ideias pela direção moral, cultural e política da sociedade. Reconhecendo o caráter estratégico da produção simbólica nas disputas pelo poder, compartilho do entendimento de Jean Paul Sartre de que a mídia desempenha os papéis de "servidores da hegemonia e guardiães da tradição". Ocupa a posição proeminente no âmbito das relações sociais, visto que fixa contornos ideológicos da ordem hegemônica, elevando o mercado à instância máxima da representação de interesses. Não raro, o discurso dominante fabricado pelos aparatos midiáticos tenta neutralizar o espaço de circulação de visões dissonantes e contestadoras. Edward Said foi preciso ao ressaltar que, enfraquecendo ou silenciando pontos de resistência, este discurso objetiva "modelar a impiedosa lógica corporativa da obtenção de lucros e o poder político em um estado de coisas normal - é assim que as coisas são -, convertendo, no processo, a resistência racional a estas noções em algo completa e praticamente irrealista, irracional, utópico, etc." (Moraes, 2010, p. 17 -18).

Imaginário social, na definição de Moraes, é a memória afetiva de uma cultura construída coletivamente. é uma dimensão da consciência humana na qual ficam explícitos interesses, conflitos e controles da vida coletiva. "O imaginário social se traduz por ideologias, símbolos, alegorias, rituais e mitos, que plasmam visões de mundo e modelam estilos de vida" (Moraes, 2010, p.30).

Nesse espaço do imaginário são introduzidas mudanças nos modos de sociabilidade, "fazendo supor que podem ser concebidos outros modelos e padrões de comportamento" de "maneira dinâmica" - o uso social das representações e das ideias (Moraes, 2010, p.31). O uso coletivo dessas representações e imagens conferem aos indivíduos a "sensação de pertencimento e estabelecem referências que definem, para os integrantes de uma comunidade, seus intercâmbios com as instituições e sua compreensão da realidade" (Brisola, 2016, p.44).

Para Moraes (2010, p.47) não existe harmonia nem homogeneidade no campo midiático, este é, na verdade, permeado de contradições, preferências, desejos e oscilações de gosto. Isso percebe-se claramente na história do MMA. Contudo, a sintonia é feita através de estratégias midiáticas, de publicidade e de um marketing mais sutil e persuasivo, que seduz, também corroborado neste fenômeno.

Ao se refletir se pode haver persuasão na formação ou alteração do gosto e se este é construído socialmente, despertado ou desenvolvido, conclui-se que a televisão pode sim com suas técnicas comunicacionais despertar o gosto por este ou aquele esporte, ou ao menos, estimular este gosto a partir das expectativas ou experiências de seus espectadores. Quando é mostrado, no reality show, o lado humano do lutador de MMA, há um claro apelo para que a audiência se amplie e mais pessoas tenham afinidades ou interesses por aquele esporte. Podemos, então, pensar nas possibilidades e conjuntura de construção deste gosto. Podemos pensar em como o gosto tem sido utilizado para fortalecer a hegemonia e alimentar o capital, utilizando, no caso do MMA, o lado entretenimento do esporte.

Schneider (2015) aponta um caminho para a compreensão dos mecanismos de formação e conformação do gosto e da sua construção dialética entre o individual e o coletivo. À primeira impressão o gosto é associado ao sentido do paladar, à 
boca, e, por consequência da necessidade da alimentação para o sustento da própria vida, à sobrevivência, mas também ao prazer. Embora todos os órgãos nos quais atuam os sentidos tenham relação com a sobrevivência e o prazer, "a sobrevivência é condição necessária para o prazer, enquanto o contrário não é verdade" (Schneider, 2015, p. 53 - 54). O paladar, entretanto, se distingue dos outros sentidos porque este requer esforço prévio dos outros sentidos. Para que o alimento seja degustado é necessário que antes alguma pessoa, o dono da boca ou outra, o recolha, prepare, conserve ou distribua. Começa aí, no trabalho indispensável para que se possa comer, a relação vital entre o gosto e os juízos de valor?” (Schneider, 2015, p. 54).

Retomando Freud, Schneider (2015) associa o sabor ao prazer, na satisfação da fome e da afetividade que se dá na amamentação. Assim pode ter sido associado o "gostar de" algum alimento, pessoa, ideias, coisas etc. ou "ter fome de" conhecimento, aventura etc. O desdobramento do termo gosto para o juízo de valor se deu através do trabalho racional cooperativo, sendo que o primeiro de todos os trabalhos foi aquele orientado para a alimentação, e "daí a utilização do termo gosto ter-se desdobrado da alimentação para todo o resto: porque é no gosto que se dá a síntese dialética entre necessidade (comer) e liberdade (escolher o alimento e o preparo), e entre prazer (degustar, desfrutar) e conhecimento (identificar, saber onde encontrar, adquirir, saber fazer, saber preservar)" (Schneider, 2015, p. 57).

Assim, fica clara a construção social do gosto. Ainda que pareça natural e de senso comum que o gosto é uma coisa pessoal, que no máximo se lamenta e não se discute, existe uma óbvia influência da historicidade, geolocalização, classe social, cultura etc. Além da influência da indústria e da comunicação. É possível então que mesmo que a princípio uma pessoa não goste de determinada coisa, por exemplo do MMA, de tanto conviver, ver, ou ouvir falar passe a gostar. A Indústria de Cultural e a Cultura de Massa (Adorno; Horkheimer, 1985) sabem disso há tempos. Quando um indivíduo é exposto com frequência a certo gosto, hábito, música ou moda, acaba por criar uma empatia ou compatibilidade com esta.

Cientificamente o gosto é diferente em cada boca. As papilas gustativas de pessoas distintas percebem a mesma comida de maneira diferente, no entanto quase todo brasileiro gosta de feijão. Por outro lado, a cada dez dias o epitélio da língua substitui as papilas gustativas. Assim o gosto pode ser adestrado. Da mesma maneira com o gosto em geral, quando o indivíduo é recorrentemente sensibilizado, principalmente se há uma conjuntura emocional envolvida (Brisola, 2016, p.95). "Há, pois, uma transcendência no gosto para além das singularidades da sensibilidade individual; tal caráter transcendente, que de certo modo compõe e às vezes se opõe à sensibilidade merece ser investigado. Ele remete ao universal (o humano) e ao particular (o étnico, o nacional etc.)" (Schneider, 2015, p. 61). Ou seja, o gosto não é fruto apenas da sensibilidade individual.

Segundo Schneider (2015), Marx enxergou que é a "prática dos sujeitos que atribui ao objeto uma dimensão humana, é a sua verdade, tanto sensível quanto intelectual, que lhe atribui um, não o sentido" e Schneider não aceita a hipótese de uma teoria estética universal, mas sim que no que diz respeito aos juízos de gosto, "é na interação entre um objeto específico e um sujeito específico - sujeito histórico, munido de sensibilidade e razão, ocupando um determinado locus social em um espaço geopolítico e em um momento histórico dados - que se estabelece não a, mas uma verdade” (Schneider, 2015, p. 63-64).

De fato há uma parcela do gosto que é individual e independente da construção social, contudo, nenhum indivíduo pode ser descolado de sua historicidade, classe social, temporalidade e espaço geopolítico (Marx; Engels, 2007). Objetos não tem sentido absolutos nem uma única verdade, do mesmo jeito não há um gosto único. A racionalidade merece crédito, porém sem se pretender "universal" e reconhecendo sua historicidade e sem descartar as especificidades e razões de cada objeto. Racionalidade e sensibilidade devem ser consideradas na análise do gosto.

O conflito entre a racionalidade e a sensibilidade ou a sensualidade, segundo Schneider, no que diz respeito ao gosto, só não aconteceria na hipótese de o gosto individual estar de acordo com um padrão coletivo e que nenhum dos dois sejam confrontados com outro padrão. Atualmente esse conflito é frequente, principalmente pela quantidade de exposição e contato com padrões diferentes, advindos de pessoas e culturas distintas. Ainda assim essa realidade não suprime a influência social e cultural sobre o gosto individual. Um brasileiro pode ter a curiosidade de provar um churrasco de morcego ou um espeto de 
escorpião depois de vê-los em algum vídeo gastronômico, contudo isso não vai suprimir sua cultural estranheza e muito menos a dos brasileiros ao seu redor. Esse desconforto está ligado à necessidade do sujeito de, ao ter seu gosto pessoal confrontado, sentir a necessidade de ser reconhecido e a frustração de não sê-lo. Schneider ainda cita La Rochechefoucauld, "Ofende mais o nosso orgulho ataques aos nossos gostos do que as nossas opiniões" (Schneider, 2015, p. 66). Existe no ser humano uma necessidade de pertencimento.

A mídia em geral e especialmente a internet facilita a aproximação nos guetos dos gostos. Por mais bizarro que seja um gosto específico de um sujeito, no oceano da internet ele encontrará uma ilha com seus iguais. Isso de certa maneira apazígua a necessidade de reconhecimento e a sensação de possuir um gosto totalmente peculiar. Mas então, porque algo desperta prazer em uns e em outros não? Porque determinada coisa é popular em um grupo e detestada por outro? Schneider aponta como uma das possíveis respostas a rede valorativa individual, tecida a partir de:

1) maior ou menor acesso do sujeito a um repertório simbólico comum e aos cânones da classe e/ou da fração de classe à qual ele pertence, bem como aos das classes ou frações de classe às quais ele não pertence, ambos os graus de acesso condicionados pela sua posição de classe;

2) as condições objetivas de apreensão (contexto da afecção) e reapreensão (novos contextos de apreensão), que têm como referência de afecção prazerosa - ou desprazerosa - o primeiro, apreensão esta que se busca reproduzir - ou não -, no esforço de carregar os novos contextos de significação e gozo equivalentes aos anteriores. Assim o sujeito pode reproduzir o cânone - se o prazer que legitima lhe satisfizer e se não houver conflito entre sensibilidade e razão -, abandoná-lo ou opor-se a ele (Schneider, 2015, p. 67 e 68).

A questão aqui é a exposição do sujeito aos objetos, de maneira positiva ou negativa, previamente determinadas por sua classe ou fração de classe. Percebemos isso na história do MMA e em suas idas e vindas à televisão até que ganhou espaço nos EUA, e voltou com o glamour do UFC. O gosto pelo esporte foi variando conforme os tipos de exposição e apelos de suas apresentações, mas, fato é que o esporte ganhou espaço e passou a ser muito lucrativo no Brasil.

\section{Conclusões sobre o Espetáculo e o Octógono: a alienação do gosto}

A relação MMA, mídias e público remete à descrição de espetáculo de Guy Debord. Em 1967 o autor faz essa descrição, e explora o aprisionamento da sociedade pela espetacularização, de uma maneira surpreendente. Essa relação entre capital, espetáculo e massa, hoje se mistura de tal forma, que quase não se reconhece mais os limites entre as partes. Desfilando pelas mídias digitais, a vida se transforma em imagens que vendem ideais e ideários. Não importa mais o ser e sim o parecer ser. A imagem passa a valer mais do que a própria vivência. É mais importante registrar em foto um acontecimento do que vivenciá-lo, como se aquilo que não é postado nas redes sociais digitais, não tivesse acontecido.

Debord "detecta o quanto a economia subsumiu a vida humana às suas próprias leis, ele corrobora a ideia de Marx de que o capital é uma entidade com vida própria que orquestra a sociedade" (Brisola, 2016 b, p.26). Nitidamente influenciado por Marx, retoma a ideia do fetichismo da mercadoria e chama esta devoção à mercadoria de "espetáculo". O espetáculo é, então, a sedução das mercadorias e as suas paixões. É nesta luta cega que cada mercadoria faz seguir sua paixão e realiza, de fato, na inconsciência do público o desejo. No caso exposto aqui a mercadoria é o MMA através da marca UFC. (Debord, 1999).

Brisola (2016b) aponta que Debord utiliza a teoria de Marx, que já havia atribuído à mercadoria características de entidade, algo que se estabelece como única, pretendendo se impor e gerar paixão. Na atualidade, com a espetacularização, quase generalizada em que está imerso o mundo, essa sedução se espalha, consciente para os mercadores e, por vezes sem ser percebida pelos consumidores. Walter Benjamin (1955) vê esse processo como algo positivo quando afirma que: "orientar a realidade em função das massas e as massas em função da realidade é um processo de imenso alcance, tanto para o pensamento 
como para a intuição" (Benjamin, 1955, p. 3). Contudo, percebemos que essa orientação subsume o indivíduo e o molda para o consumo e o gosto.

O espetáculo envolve o espectador e suas atividades, e "a imagem acaba por se tornar real, sendo causa de um comportamento real, e a realidade acaba por se tornar imagem" (Jappe, 1999, p.21). Assim, o indivíduo seduzido pelos meios de comunicação e empático com a violência ou estrutura da luta, passa a admirá-la e consumi-la. No caso, o gosto por esse espetáculo não reflete toda sociedade, mas uma parte dela, por isso os conflitos ao longo dos anos. Contudo, como demonstrado através da narrativa histórica aqui apresentada, para ser aceito o produto MMA se conforma para minimizar os conflitos e acaba ganhando espaço e respeito, saindo da quase marginalidade ou rejeição para ser aceito enquanto esporte e espetáculo.

O que favorece o espetáculo é que parte dos espectadores ainda reage cega pelo fetiche, pela paixão. Esses indivíduos participam do espetáculo, o alimentam e seguem o roteiro do espetáculo. A agenda do UFC passa a satisfazer as ânsias do público que devolvem sucesso e dinheiro ao espetáculo. Os atores das lutas passam a ser vistos como ídolos, humanizados pelos realitys UFC e admirados por sua força e determinação.

Debord (1999, p. 15), por sua vez, afirma que, o espetáculo é "o resultado e o projeto do modo de produção existente". O espetáculo do Octógono satisfaz as expectativas de lucro dos investidores e a ânsia por circo dos espectadores. O “coração da irrealidade da sociedade real" se projeta no gosto pelo espetáculo que alimenta o desejo.

Sob todas as suas formas particulares de informação ou propaganda, publicidade ou consumo direto do entretenimento, o espetáculo constitui o modelo presente da vida socialmente dominante. Ele é a afirmação onipresente da escolha já feita na produção, e no seu corolário - o consumo (Debord, 1999, p.15). E é no consumo que o MMA desenvolve seu produto e sua fama.

Se a sociedade é regida pelos modos de produção capitalista e de consumo do qual o desejo é a mola propulsora, os meios de comunicação são a arma mor do espetáculo, é através da comunicação, em todas as suas formas, que o espetáculo conquista seu público e o cativa. Neste ponto a questão é perceber que, independente da legitimidade esportiva de qualquer modalidade, há uma apropriação do capital desta atividade. Contudo, o que percebemos em relação ao MMA é que ele, desde o princípio foi idealizado como espetáculo, como produto a ser consumido e transmitido. Como esporte moldado às paixões e cativante de gostos, que se esmerou ao longo de 69 anos (de 1951 a 2020, quando foi escrito este texto) para alcançar seus objetivos e glória. E ainda estamos presenciando a ascensão do MMA.

\section{Referências}

Adorno, Theodor W.; Horkheimer, Max. (1985) Dialética do esclarecimento. Fragmentos Filosóficos. Tradução de Guido Antonio de Almeida. Rio de Janeiro: Jorge Zahar. 254p.

Awi Fellipe. (2012) Filho teu não foge à Luta-Como brasileiros transformaram o MMA em fenômeno no mundo. Rio de Janeiro, intrínseca, p. $20-337$.

Awi, Fellipe. (2013). O homem que não sentia dor. TRIP. (22), 12 junho. https://revistatrip.uol.com.br/trip/o-homem-que-nao-sentia-dor.

Benjamin, Walter. (1955). A Obra de Arte na Era da Sua Reprodutibilidade Técnica. Ensaio traduzido em português por José Lino Grünnewald e publicado na coleção Os pensadores, da Abril Cultural.

Botelho, Rafael Guimarães; Souza, José Maurício Capinussú de. (2007). Bullying e educação física na escola: características, casos, conseqüências e estratégias de intervenção. Revista de Educação Física, Rio de Janeiro, (139), 58-70.

Brasil, 1727/97, de 01 de outubro de 1997. Proíbe em todo o estado do Rio de Janeiro a competição denominada “VALE-TUDO” e dá outras providências, Rio Janeiro. http://alerjln1.alerj.rj.gov.br/sepro.nsf/966b2c48881f31003256502005063cb/.65f16ef31bb6e203256502005063cb/65f16ef31bb6e2032565250069ce6cOpenDo cument.

Brisola, Anna Cristina. (2016). A ágora digital, a competência crítica em informação e a cidadania ampliada: uma construção possível. (Master thesis). Rio de Janeiro: Instituto Brasileiro de Informação em Ciência e Tecnologia, Universidade Federal do Rio de janeiro. 
Brisola, Anna Cristina. (2016). A sociedade contemporânea e o lado épico do deus capital, um espetáculo debordiano - as novas relações sociais e informacionais. Anais do VI Encontro Nacional da Ulepicc-Brasil-Brasília - 9 a 11 Nov. 2016 (b). p. 24-35.

Calhoun, Donald W. (1987). Sport, Culture and Personality. Illinois: Human Kinetics.

Camilo, Juliana A. de Oliveira; Spink, Mary Jane Paris. (2018). As Artes Marciais Mistas (MMA): esporte, espetáculo e economia. Revista de Artes Marciales Asiáticas, León, 13(1), 20-34. http://revpubli.unileon.es/ojs/index.php/artesmarciales/article/view/5188 doi:http://dx.doi.org/10.18002/rama.v13i1.5188.

Capurro, Rafael; Hjorland, Birger. (2007). O conceito de Informação. Perspec. Ci. Inf., v. 12, n. 1, p. 148-207, jan./abr. 2007.

Carmo, Gonçalo Cassins Moreira do. (2016). It’s show time: violência e emoções no Mixed Martial Arts (MMA 1995 - 2016). Tese (Doutorado Ciências sociais) Universidade Estadual de Ponta Grossa - Ponta Grossa, Paraná. 192f.

Castells, Manuel. (2003). Internet e sociedade em rede. In Dênis de Moraes (Org.), Por uma outra comunicação (pp. 255-287). Rio de Janeiro, Brasil: Record.

Debord, Guy. (2003). A sociedade do espetáculo. Guy Debord (1931-1994).

Gomes, Luciani, A luta que move milhões. Istoé Independente, [S. i.], $13 \quad$ agosto 2010. http://www.istoe.com.br/reportagens/95191_a+luta+que+move+milhoes.

Hayeck, Cynara Marques. (2009). Refletindo sobre a violência. Revista Brasileira de História e Ciências Sociais, [S. i.], n.1, Jul. 2009. http://www.Rbhcs.com/index_arquivos/Artigo.Refletindo\%20sobre\%20a\%20viol\%C3\%AAncia.pdf.

Jappe, Anselm. (1999). Guy Debord, tradução de 1 r: ici D. Poleti. - Petrópolis, RJ: Vozes.

Marx, Karl; Engels, Friedrich. (2007). A ideologia alemã: crítica da mais recente filosofia alemã em seus representantes Feuerbach, B. Bauer e Stirner, e do socialismo alemão em seus diferentes profetas (1845-1846) / Karl Marx, Friedrich Engels; supervisão editorial, Leandro Konder; tradução, Rubens Enderle, Nélio Schneider, Luciano Cavini Martorano. São Paulo:

Boitempo.

Minayo, Maria Cecília de Souza; Souza, Edinilsa Ramos de. (1998). Violência e saúde como um campo interdisciplinar e de ação coletiva. História, Ciência Saúde - Manguinhos, Rio de Janeiro, 4(3), 513-531.

Mocarzel, Rafael Carvalho da Silva. (2011). Artes Marciais e Jovens: violência ou valores educacionais? Um estudo de caso de um estilo de Kung-Fu. Tese (Mestrado Ciências da atividade física) Universidade Salgado de Oliveira - Universo, Niterói, Rio de Janeiro. 108f.

Mocarzel, Rafael Carvalho da Silva; Columá, Jorge Felipe. (2020). Lutas e Artes Marciais: aspectos educacionais, sociais e lúdicos. $2^{\text {a }}$ ed. Manaus: OMP.

Moraes, Denis de. (2010). Comunicação, hegemonia e contra-hegemonia: a contribuição teórica de Gramsci. Dossiê comunicação e política. Revista Debates, Porto Alegre, 4(1), 54-77, http://www.seer.ufrgs.br/debates/article/viewFile/12420/8298.

Murad, Mauricio. (2007). A violência e o futebol: dos estudos clássicos aos dias de hoje. Rio de Janeiro: FGV.

Murad, Mauricio. (2009). Sociologia e educação física: diálogos, linguagens do corpo, esportes. Rio de Janeiro: FGV, p. 204.

Schneider, Marco. (2015). A Dialética do Gosto. Informação, música e política. Rio de Janeiro: Circuito / Faperj.

Schneider, Marco. Internet e Cidadania nas periferias do Rio de Janeiro. In: Estudos em Comunicação, n 12, $279-292$, Portugal, dez. 2012. http://www.ec.ubi.pt/ec/12/pdf/EC12-2012Dez-14.pdf.

Takao, Fabio Quio. (2012). Ufc na globo: Apogeu ou fim do MMA? TerraMagazine, 12 abril. http://terramagazine.terra.com.br/mmamanoamano/blog/2012/04/12/ufc-na-globo-apogeu-ou-fim-do-mma. Tubino, Manoel José Gomes. (1993). O que é esporte. São Paulo: Brasiliense.

Vasques, Daniel Giordani. (2013) As artes marciais mistas (MMA) como esporte moderno: entre a busca da excitação e a tolerância à violência. Esporte e Sociedade. (22). http://www.uff.br/esportesociedade/pdf/es2203.pdf. 